\title{
AN ALARMING PANDEMIC COVID-19 IN ASIA -AN OBSERVATIONAL STUDY
}

\author{
Raj Kumar ${ }^{1}$ \\ ${ }^{1}$ Mch. PhD, DSc., \\ Vice-chancellor,
}

Uttar Pradesh university of Medical Sciences,

Saifai, Etawah,

Uttar Pradesh, India.

\section{Suraj kumar ${ }^{* 3}$}

${ }^{3} \mathrm{PhD}$., Associate Professor \& Head,

Dept. of Physiotherapy,

Faculty of Paramedical sciences,

Uttar Pradesh University Of Medical Sciences,

Saifai, Etawah,

U.P, India.

\author{
Gowrishankar Potturi ${ }^{2}$ \\ ${ }^{2} \mathrm{PhD}$., Lecturer, \\ Department Of Physiotherapy, \\ Faculty Of Paramedical Sciences, \\ Uttar Pradesh University Of Medical Sciences, \\ Saifai, Etawah, \\ U.P, India.
}

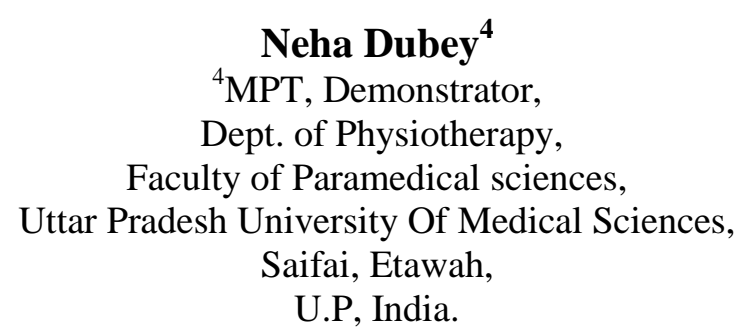

${ }^{4}$ MPT, Demonstrator,

Dept. of Physiotherapy,

U.P, India.

\author{
Arushi Kumar ${ }^{5}$ \\ ${ }^{5}$ Medical Researcher, \\ A/82, Omex City, \\ Lucknow, \\ Uttar Pradesh, \\ India.
}

Article DOI: https://doi.org/10.36713/epra4414

\begin{abstract}
Back ground \& Purpose: Many countries in Asia as well as developed countries like England, Australia and USA were attacked by the rampant COVID-19.This observational study was conducted to analyze the rate of transmission, death to case ratio, doubling time, role of temperature and other preventive measures on these variables.

Methodology: Data of the variables were collected from World Health Organization online daily progress reports on COVID19 and other reliable Internet sources on a daily basis from 30-03-2020 till 20-04-2020.

Results \& Conclusion: The transmission was maximum in Turkey, Iran, China, Russia, India, Israel, Japan, South Korea, Saudi Arabia, and Pakistan whereas minimum in Yemen, Bhutan, Laos, Timor-Leste, Nepal, Mongolia, Syria, Maldives, Myanmar, and Cambodia. There were no confirmed cases reported in Turkmenistan, Tajikistan and North Korea. Temperature didn't appear to be influencing the transmission and death rate due to COVID-19 in Asian countries. There is a positive correlation between the environmental temperatures, preventive measures, lock down and the doubling time of COVID-19 in Asian countries.

KEY WORDS: - COVID -19, ASIA, Doubling time, Death - to - case ratio, Temperature
\end{abstract}




\section{INTRODUCTION}

The outbreak of mysterious pneumonia in December-2019 characterized by fever, dry cough, fatigue and occasional gastrointestinal symptoms in the city of Wuhan, Hubei province in China ${ }^{1}$. The World Health Organization (WHO) has declared the COVID19 as a health emergency and pandemic. The pathogen of this baffling pneumonia was identified as novel betacorona virus disease named as COVID-192,3. The exact genesis, environment and natural reservoir of the 2019$\mathrm{nCoV}$ is still dubious, although it is believed that the virus is zoonotic and bats are the delinquent. ${ }^{4,5}$

Asia is Earth's largest and most populous continent located in the eastern and Northern Hemispheres. It shares its borders with Europe and Africa. It is notable for its dense and large human settlements constituting $60 \%$ of world's population ${ }^{6}$. COVID-19 had its epicenter at Huanan seafood whole sale market in Wuhan, China, Asia, and strew all over the world by mid of March, 2020. Many countries in Asia as well as advanced developed countries like England, Australia and USA were attacked by the rampant spreading of the disease ${ }^{7}$

In this observational study, we analyzed the rate and type of transmission, death-to-case ratio, and doubling time of COVID-19 cases in various Asian countries from 30-03-2020 till 20-04-2020. We also analyzed the effect of temperature and preventive measures taken by various Asian countries to restrain the transmission and death-to case ratio of the disease.

\section{METHODOLOGY}

We collected the data from World Health organization online daily situation reports on COVID19 and from other reliable Internet sources on a day to day basis from 30-03-2020 till 20-04-2020. Daily Confirmed cases were recorded along with number of Deaths, number of recoveries in the Asian countries. We also recorded the date of first confirmed case, type of transmission, monthly average temperatures for the month of February, March and April 2020, date of implementation of lock down along with the preventive measures taken by the respective administrations of the countries.

The death- to - case ratio was calculated by the formula $^{8}$ (Number of Deaths due to COVID-19 on 2004-2020/ Number of cases of COVID-19 reported on 20-04-2020) x100.

The doubling time was calculated by the following procedure

For each Asian country, the numbers of confirmed cases $(\mathrm{Nd})$ on any given day $(\mathrm{n})$ were then compared with number of confirmed cases on following subsequent days, until the number of cases exceeded
$2 \mathrm{xNd}$. Interpolating linearly between day $(\mathrm{m})$, where (m) is the day $2 \times \mathrm{xd}$ occurred and day $(\mathrm{m}-1)$ generated the decimal number of days taken to double Nd. The process was then stepped forward starting at day (m), to find the number of days required for doubling that number of COVID-19 cases, repeating through the dataset ${ }^{9}$.

\section{RESULTS}

After, collecting the data, from 30-03-2020 till 20-04-2020 on a day to day basis, it was revealed that the maximum number of confirmed cases were reported in Turkey (90980), Iran (83505), China(82747), Russia(47121), India(18539), Israel(13713), Japan(11135), South Korea (10674), Saudi Arabia(10484), Pakistan(8892). The minimally affected countries by number of confirmed cases were Yemen (01), Bhutan(05), Laos(19), Timor-Leste(22), Nepal(31), Mongolia(33), Syria(39), Maldives(69), Myanmar(119), Cambodia(122). There were no confirmed cases reported in Turkmenistan, Tajikistan and North Korea. (Fig 1-See Appendix)

The average temperatures for the months of February, March and April in the countries where maximum number of confirmed cases were reported in degree Celsius are Turkey $(3.6,6.7,11.5)$, Iran (3.5,10.1,15.6), China( -0.4,7.1,13.6), Russia(-18,9.8,0.8), India( $17.3,23.6,27.4)$, Israel( $11.2,14.2,18)$, Japan (3.9, 7.1, 12.2), South Korea(-0.9, 5.3, 11.5), Saudi Arabia( 15.6, 21, 25.1), Pakistan (10.5, 17.9, 23.2) and for Minimally affected countries the temperatures recorded are Yemen(23.9, 25.4, 27), Bhutan $(7.5,12.7,15.5)$, Laos(20.8, 24.8,26.9) TimorLeste $(31.1,31.2,31.5)$, Nepal $(9.9,16.4,20.7)$, Mongolia(-20.8,-8, 1.5), Syria $(7,11.5,16.3)$, Maldives (27.6, 27.8, 28.3), Myanmar(21.7, 26.5, 28.9), and Cambodia $(25.1,28.1,29.1)$.

The death-to- case ratio was calculated and the Maximum rate was found in Indonesia (8.72), Syria (7.6), Philippines (6.6), Iran (6.2), China (5.5), Iraq (5.2), Myanmar (4.2), Afghanistan (3.5), Bangladesh (3.4), and India (3.19). The minimal Death to case ratio was found in Singapore (0.13, Qatar (0.14), Uzbekisthan (0.30), Bahrain (0.36), Kuwait (0.45), Oman (0.49), UAE (0.59), Palestine (0.66), Brunei (0.72), and Russia (0.8). (Fig 2-See Appendix)

The doubling time was calculated in the countries where Maximum number of confirmed cases and Minimal number of Confirmed cases were recorded. The doubling time during the period of 30-032020 to 20-04-2020 was Turkey $(3.5,3.5,7.5)$, Iran ( 16.5), Russia (3.5, 3.5, 4.5,3.5), India $(3.5,2.5,4.5,6.5)$, Israel (5.5), Japan ( 6.5,5.5), South Korea (cases were 
not doubled during the study time frame), Saudi Arabia (6.5,6.5,5.5), Pakistan (5.5, 9.5). (Fig.2-See Appendix)

\section{DISCUSSION}

From this observational study, it was revealed that the maximum numbers of cases were reported in the countries of Turkey, Iran, China, Russia, India, Israel, Japan, South Korea, Saudi Arabia, and Pakistan. All these Asian countries have different temperature zones. The temperatures recorded in these countries in the month of March range from -9.8(Russia) to +23.6 (India) degree Celsius ${ }^{10}$, and in the month of April the temperatures range from Russia (0.8), to India (27.4) degree Celsius. The Maximum recorded temperature in the Month of April was recorded in Timor- Leste $\left(31.5^{\circ} \mathrm{C}\right)$ where the cases are minimally recorded $(22)$. The minimal temperature was recorded in Russia ( 0.8 ${ }^{\circ} \mathrm{C}$ ) where the Maximum number of cases were confirmed (47121). On the contrary, the temperatures in Mongolia were similar to Russia $\left(1.5^{\circ} \mathrm{C}\right)$ but the cases were minimally found. From this study we observed that the temperature had no role in transmission because the cases were confirmed in diversified temperature zones. In the study by Ye Yao et.al (2020) culminated that there is no association of COVID-19 transmission with temperature or $\mathrm{UV}$ radiations ${ }^{11}$.

The death to case ratio was maximal in Indonesia and minimum in Singapore, while the average temperature recorded in Indonesia in the month of April is $26.7^{\circ} \mathrm{C}$ and in Singapore $27.4^{\circ} \mathrm{C}$. The deathto-case ratio was 0 in Timor-leste where the temperature was recorded maximum and the minimal temperature was recorded at Russia where the death -to -case ratio being 0.8 . It is evident from our study, that the temperatures had no role to play on death-case-ratio as the number of deaths recorded either not unified in same temperature zones or diversified in different temperature zones. In the study correlation between temperature and COVID-19 (Suspected, confirmed and death) cases based on machine learning analysis by Mohammad Khubeb Siddiqui et.al (2020) concluded that the temperature had diversified trends on deaths due to COVID-19, hence the transmission and deaths due to COVID-19 cannot be attributed to the temperatures alone ${ }^{12}$.

Most of the Asian countries have called on for a lockdown. The lock down is a preventive measure adopted by many countries to reduce the doubling time. Turkey didn't apply it during our observation time frame. But the doubling time in Turkey without lockdown has declined from 3.5 to 7.5 days due to effective preventive measures taken by the administrators like using special disinfectants to keep surroundings clean against virus threat, travelling and gathering restrictions, screening of international passengers, closure of public malls and educational institutions. The decline in the doubling time can also be attributed to temperatures in Turkey as temperatures were increasing in the month of April. The latest research on COVID-19 by Barbara Oliveiros et.al (2020) concluded that there may be delay in the doubling time as the temperatures rises, which is similar to our study ${ }^{13}$.

The doubling time in Iran was 16.5 days. Iran too didn't implement lock down measures, but strict social distancing and closure of public hotspots, restriction on travelling were implemented. In this country too, the temperatures raised in the month of April leading to delay in the doubling time. In china, India, Pakistan, the doubling time has been delayed. There was increase in temperatures in the month of April in these countries. These countries also applied Lock down measures.

The most common preventive measures taken in these countries are closure of educational institutes, thermal screening of international passengers, deployment of army to ensure social distance, stoppage of transportation, ban on international travel, sterilization campaign, home quarantine, and ban on social gathering. In most of the Asian countries it was found that the there is Local transmission of the disease except for countries like Bhutan, Mongolia, Nepal and Syria. In Timor-Leste, Kazakhstan the transmission is still under investigation. Even though most of the countries went into Lock down, Countries like Bahrain, Bhutan, Brunei, Cambodia, Cyprus, Indonesia, Iran, Israel, Jordan, Laos, Lebanon, Maldives, Mongolia, South Korea, Taiwan, Timore-leste, Turkey, Turkmenistan and Yeman have not applied complete Lock down Measures.

Health services are usually considered synonymous with preventive, curative, protective, rehabilitative and restorative services ${ }^{14}$. Lock down is not a panicking situation but an effective preventive measure ${ }^{15}$ to control the spread of COVID-19 as there is no evident and efficient treatment options available till date, hence prevention is the only solution.

\section{CONCLUSION}

The transmission of COVID-19 was reported maximum in Turkey, Iran, China, Russia, India, Israel, Japan, South Korea, Saudi Arabia, and Pakistan where as minimum reported in Yemen, Bhutan, Laos, TimorLeste, Nepal, Mongolia, Syria), Maldives, Myanmar, and Cambodia. There were no confirmed cases reported in Turkmenistan, Tajikistan and North Korea. Temperature does neither appear to an influencing factor in the transmission nor in deaths due to COVID19 in Asian countries. There is a positive correlation 
between the environmental temperatures, preventive measures, Lock down and the doubling time of COVID-19 among Asian countries, which decreased significantly following implementation of effective preventive measures.

\section{ACKNOWLEDGEMENT}

The authors acknowledge the authorities of Uttar Pradesh University of Medical Sciences, Saifai,

Etawah, Uttar Pradesh for approval and encouragement

SOURCE OF FUNDING: NIL

CONFLICTS OF INTEREST: The authors declare no conflicts of Interest

\section{APPENDIX}

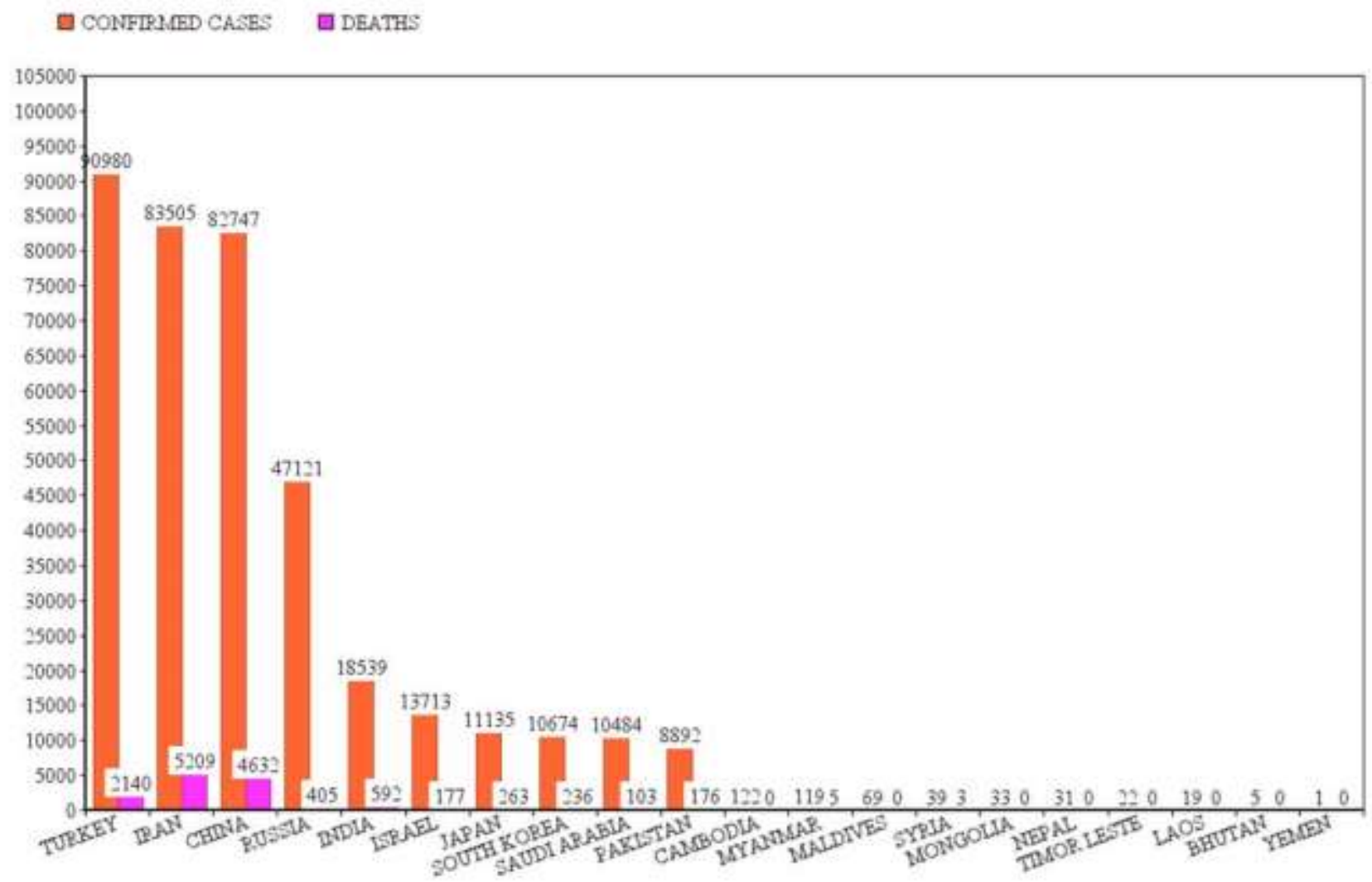

FIG 1 NUMBER, OF CONFIPIIED CASES AND NUMBER. OF DEATHS IN ASLAN COUNTRIES AS ON 30-04-2030 DUE TO COVID-19 
- Temperatures $\quad-$ Doubling Time $\quad \square$ Death to case ratio

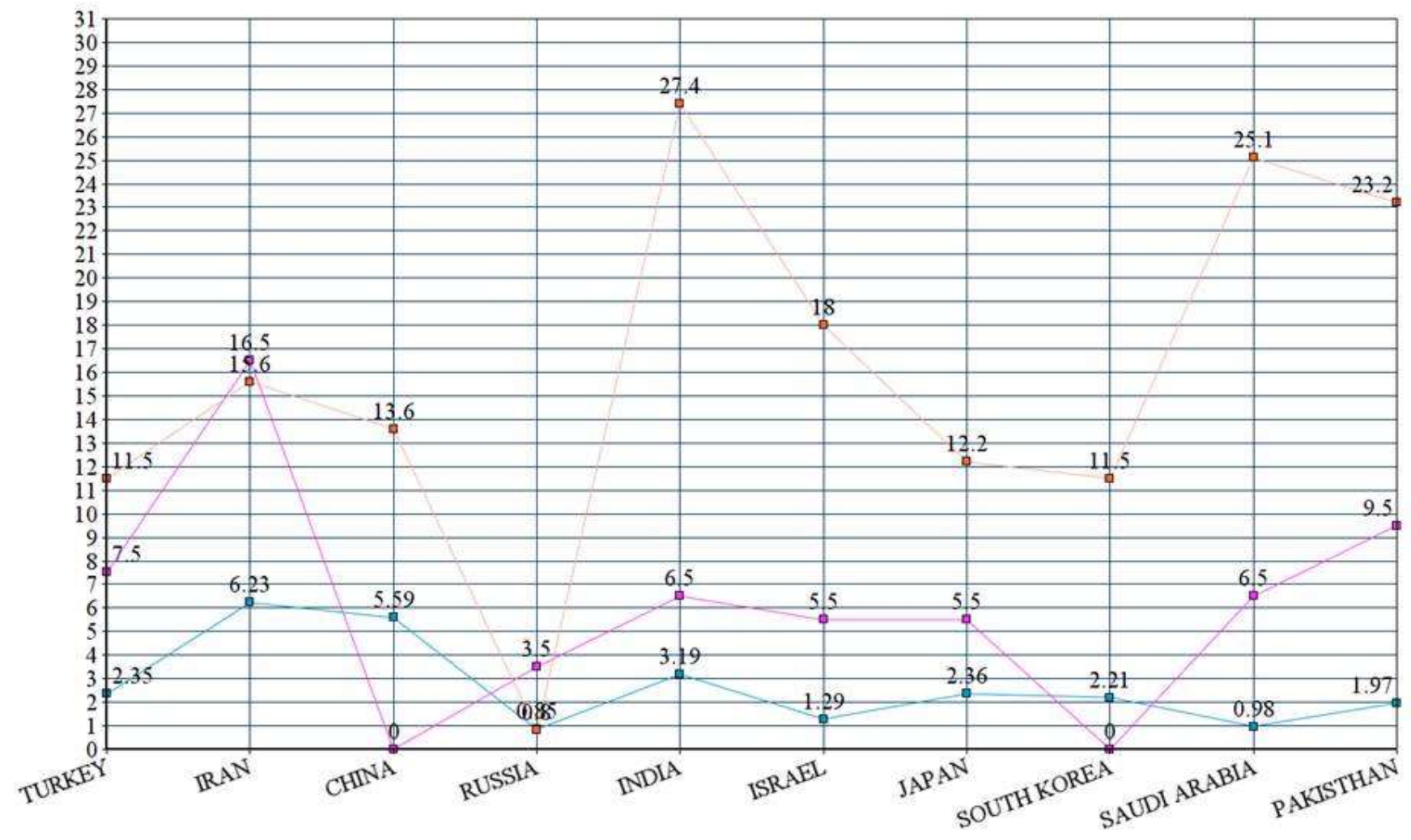

Fig2: Relation between Temperature, Doubling time and Death to case ratio in Maximally affected ASIAN countries due to COVID-19 from 30-03-2020 to 20-04-2020

\section{REFERENCES}

1. Huang $C$, Wang $Y$, Li X, Ren L, Zhao J, Hu y (2020), Clinical features of patients infected with 2019 novel corona virus in Wuhan, China.Lancet. DOI: 10.1016/S0140-6736(20)30183-5.

2. N. Zhong, B. Zheng, Y. Li, L. Poon, Z. Xie, K. Chan (2003).Epidemiology and cause of severe acute respiratory syndrome (SARS) in Guangdong, People's Republic of China.

3. J. Cui, F. Li, Z.-L. Shi (2013) Origin and evolution of pathogenic corona viruses Nat Rev Microbiol, 17 (3), pp: 181-192.

4. Perlman S. Another decade, another corona virus.N Engl J Med2020DOI: 10.1056/NEJMe2001126

5. Zhu N, Zhang D, Wang W, Li X, Yang B, Song J (2020), $A$ novel coronavirus from patients with pneumonia in China, 2019.N Engl J MedDOI: 10.1056/NEJMoa2001017

6. "Population of Asia. 2019 demographics: density, ratios, growth rate, clock, rate of men to women". www.populationof.net. Retrieved 2 June 2019.
7. World Health Organization Novel Corona virus (2019nCoV) Available at https://www.who. int/emergencies/diseases/novel-coronavirus-2019. Accessed April 24, 2020

8. CENTERS FOR DISEASE CONTROL AND PREVENTION,www.cdc.gov, (online),18May, 2012, https://www.cdc.gov/csels/dsepd/ss1978/lesson3/section3 .html, reviewed on 25-04-2020.

9. Nunes-Vaz, R., 2020. Visualising the doubling time of COVID-19 allows comparison of the success of containment measures. Global Biosecurity, 1(3), p.None.

10. TIME AND DATE.COM, timeanddate.com (online), Norway, 14, April, 2020, https://www.timeanddate.com/weather/@ 1278629/climat $e$.

11. Ye Yao, Jinhua Pan, Zhixi Liu, Xia Meng, Weidong Wan g, Haidong Kan, Weibing Wang 2020) European Respiratory Journal, 2000517

12. Siddiqui, Mohammad Khubeb \& Morales-Menendez, Ruben \& Gupta, Pradeep \& Iqbal, Hafiz \& Hussain, Fida \& Khatoon, Khudeja \& Ahmad, Sultan. (2020). 
Correlation Between Temperature and COVID-19 (Suspected, Confirmed and Death) Cases based on Machine Learning Analysis. Journal of Pure and Applied Microbiology. 14.

13. Oliveiros, Bárbara \& Caramelo, Liliana \& Ferreira, Nuno \& Caramelo, Francisco. (2020). Role of temperature and humidity in the modulation of the doubling time of COVID-19 cases. 10.1101/2020.03.05.20031872.

14. Rajesh Bhatia, Priya Abraham (2020) Time to revisit national response to pandemics, Indian J Med Res 151, pp: 111-113.

15. Yuan Z, Xiao Y, Dai Z, Huang J \& Chen Y (2020) A simple model to assess Wuhan lock-down effect and region efforts during COVID-19 epidemic in China Mainland [Submitted]. Bull World Health Organ. E-pub: 02 doi: http://dx.doi.org/10.2471/BLT.20.254045 